\title{
C.E.R.A. maintains stable hemoglobin in Latin American patients on dialysis
}

\author{
Kleyton Bastos • Luis Antonio Lucarelli • Elizabeth De Francesco-Daher • \\ Roberto Pecoits Filho • Carlos Henríquez • Beatriz Espinoza • Ignacio Villanueva • \\ Emma Schwedt $\cdot$ Ruben Schiavelli $\cdot$ Ricardo Correa-Rotter
}

Received: 14 May 2012/ Accepted: 13 August 2012/Published online: 19 September 2012

(C) The Author(s) 2012. This article is published with open access at Springerlink.com

\begin{abstract}
Background C.E.R.A. is a continuous erythropoietin receptor activator with characteristics that permit a once-monthly schedule of administration for the maintenance treatment for chronic kidney disease (CKD) patients. The main objective of this study was to assess the maintenance of $\mathrm{Hb}$ concentration with once-monthly intravenous and/or subcutaneous C.E.R.A. therapy in Latin American dialysis patients with chronic renal anemia previously treated with epoetin alfa s.c or i.v 1-3 times per week.

Methods This was a single-arm, open-label, multicenter, 32-week study of anemic patients with CKD previously treated with epoetin alfa sc or iv 1-3 times
\end{abstract}

\section{K. Bastos}

CLINESE-Centro de Nefrologia de Sergipe,

Brazil Medserv, Sao Paulo, Brazil

\section{A. Lucarelli}

Hospital Universitário Walter Cantídio, Fortaleza, Brazil

E. De Francesco-Daher

UFC, Fortaleza, Brazil

R. P. Filho

PUC-PR, Curitiba, Brazil

C. Henríquez

Centro de Diálisis de Occidente, Maracaibo, Venezuela

B. Espinoza

Médica Sur Fresenius Medical Care, Mexico DF, Mexico per week. After a 4-week screening period, during which mean $\mathrm{Hb}$ levels were maintained between 10.5 and $12.5 \mathrm{~g} / \mathrm{dL}$ on their previous erythropoiesis stimulating agent, eligible patients entered a 16-week C.E.R.A. dose titration period followed by a 4-week efficacy evaluation period (EEP) and a 28-week safety follow-up. The starting dose of C.E.R.A. was based on the previous dose of epoetin alfa. Doses of C.E.R.A. were then adjusted to maintain $\mathrm{Hb}$ levels within $\pm 1.0 \mathrm{~g} / \mathrm{dL}$ of the reference concentration and between 10.5 and $12.5 \mathrm{~g} / \mathrm{dL}$. The $\mathrm{Hb}$ reference concentration was defined as the mean of all $\mathrm{Hb}$ levels during screening. The primary end point was the proportion of patients maintaining a mean $\mathrm{Hb}$ concentration

\footnotetext{
I. Villanueva

Fundación Leonor Goelkel, Bogotá, Colombia

E. Schwedt

Centro de Diálisis-Asociación Española, Montevideo, Uruguay

R. Schiavelli

Hospital General De Agudos Dr. Cosme Argerich, Buenos Aires, Argentina

R. Correa-Rotter ( $\square)$

Departamento de Nefrología y Metabolismo Mineral, Instituto Nacional de Ciencias Médicas y Nutrición

Salvador Zubirán, Vasco de Quiroga 15, Tlalpan, Mexico DF 14000, Mexico

e-mail: correarotter@prodigy.net.mx
} 
(g/dL) within $\pm 1 \mathrm{~g} / \mathrm{dL}$ of their reference $\mathrm{Hb}$ and between 10.5 and $12.5 \mathrm{~g} / \mathrm{dL}$ during the EEP.

Results A total of 163 patients from 27 centers in Argentina, Brazil, Chile, Colombia, Ecuador, Mexico, Peru, Uruguay, and Venezuela entered the treatment period and 102 completed the prescribed course of C.E.R.A. Forty-five patients $(43.7 \%)$ maintained a mean $\mathrm{Hb}$ concentration within $\pm 1 \mathrm{~g} / \mathrm{dL}$ of their reference $\mathrm{Hb}$ value and between 10.5 and $12.5 \mathrm{~g} / \mathrm{dL}$ during the EEP. The median monthly dose remained constant at $120 \mu \mathrm{g}$ during the titration period and during the EEP. On the average, there were only 2.3 dose changes per patient in 28 weeks of treatment, covering 7 C.E.R.A. scheduled administrations. $53 \%$ of all dose changes were dose decreases, $47 \%$ increases. A total of 10 AEs and 4 SAEs were considered to be related to the study treatment.

Conclusions Once-monthly C.E.R.A. treatment effectively maintains stable $\mathrm{Hb}$ concentrations in patients with chronic renal anemia undergoing dialysis with a good safety and tolerability profile.

Keywords Anemia - C.E.R.A. · Chronic kidney disease $\cdot$ Hemoglobin

\section{Introduction}

Anemia is a common complication in patients with chronic kidney disease (CKD), which can adversely affect patients' quality of life [1,2], as well as their risk of cardiovascular events [2] and death. Particularly in Latin America, a region with limited access to health care for a high proportion of the population [37], and in which patients frequently enter into care at an advanced stage of disease, the effects of CKD and associated anemia have substantial impact on quality of life, morbidity, and mortality. With regard to health care access in this region, it is important to distinguish between the technological and the financial ability to provide treatment. Although the knowhow and technology are present and allow adequate treatment in most of Latin America, limited funding of health providers has in conjunction with a scarce number of nephrologists in some countries, had the effect of restricting access to health care in many nations.
Erythropoiesis stimulating agents (ESAs) are effective in treating anemia and are associated with improved quality of life [1] and patient outcome [8]. However, the short dosing interval of conventional ESAs, and the more frequent injections (1-3 times per week) for epoetin alfa and epoetin beta [9], constitutes a burden for patients and puts a strain on health care resources.

One strategy to decrease the burden caused by frequent ESA administration is the development of ESAs with longer dosing intervals. C.E.R.A. is a continuous erythropoietin receptor activator with a half-life of about $130 \mathrm{~h}$ [10]. C.E.R.A. also has a lower binding affinity for the erythropoietin receptor and exhibits lower systemic clearance compared to conventional ESAs [10]. Together, these features permit a once-monthly schedule of administration for the maintenance treatment for CKD patients.

The hemoglobin $(\mathrm{Hb})$ levels of dialysis patients vary substantially over time, even when receiving ESA maintenance treatment, and this fluctuation has been shown to be associated with increased hospitalization events and mortality [11-13]. There are a variety of causes, but the fluctuation seems to be most closely related to frequent ESA dose changes, iron treatment practices, and hospitalization/clinical complications $[11,14]$. In addition, patients with advanced CKD typically present with high rates of oxidative stress, inflammation, and diminished biological capacity, which also contribute to a high rate of $\mathrm{Hb}$ fluctuation and associated adverse effects observed in this population [15].

In patients receiving ESA therapy, the production of erythrocytes places a high demand on functional iron supply. It is therefore important that ESA therapy be accompanied by an evaluation, and if necessary supplementation, of patient iron levels in such patients. The KDOQI clinical practice guidelines recommend assessing both the level of iron stores and the adequacy of iron for erythropoiesis by measuring serum ferritin concentration and transferrin saturation, respectively [16].

The main objective of this study was to assess the maintenance of $\mathrm{Hb}$ concentration with once-monthly intravenous and/or subcutaneous C.E.R.A. therapy in dialysis patients with chronic renal anemia previously treated with epoetin alfa. A secondary objective was to evaluate the safety and tolerability of intravenous and/ or subcutaneous C.E.R.A. 


\section{Patients and methods}

Patients

Patients 18 years or older who presented with chronic renal failure, an $\mathrm{Hb}$ concentration between 10.5 and $12.5 \mathrm{~g} / \mathrm{dL}$, and an adequate iron status (serum ferritin $>100 \mathrm{ng} / \mathrm{mL}$ or $T_{\mathrm{SAT}}>20 \%$ or hypochromic red cells $<10 \%$ ), as well as same dose of epoetin alfa maintenance treatment for the previous 2 months were eligible for inclusion in the study. Additional eligibility criteria included regular, long-term dialysis therapy with the same mode of dialysis for at least the previous 3 months and a $\mathrm{Kt} / \mathrm{V}$ of 1.8 for peritoneal dialysis or 1.2 for hemodialysis at screening. Patients were excluded from study participation if they received a blood transfusion during the previous 2 months or presented with poorly controlled hypotension, gastrointestinal bleeding, active malignant disease, hemolysis, hemoglobinopathies, folic acid deficiency, vitamin B12 deficiency, platelet count $>500 \times 10^{9} / \mathrm{L}$ or $<100 \times$ $10^{9} / \mathrm{L}$, or pure red cell aplasia.

Written informed consent was provided by all subjects and an independent ethics committee approved the study. The study was conducted in accordance with good clinical practice guidelines and the Declaration of Helsinki. Subjects who wished to withdraw from the study could do so at any time without the need to justify their decision, and investigators were permitted to withdraw a subject at any time if it was felt to be in the best interest of the subject.

Study medication

C.E.R.A. (F. Hoffmann-La Roche Ltd., Basel, Switzerland) was provided as an injectable solution in sterile prefilled syringes containing 40, 50, 60, 100, $120,150,200$, or $250 \mu \mathrm{g}$ each in $0.3 \mathrm{~mL}$ solution. C.E.R.A. was intravenously and/or subcutaneously administered once every 4 weeks (Q4W). The starting dose of C.E.R.A. for each patient was based on the dose of epoetin alfa, administered in the week preceding the switch to C.E.R.A.

Once the subjects were enrolled, patients with serum ferritin $<100 \mathrm{ng} / \mathrm{mL}$ and $T_{\mathrm{SAT}}<20 \%$ received iron supplementation. The choice of iron supplement and mode of administration were according to standard practice of the participating centers. Iron supplementation in individual patients was temporarily discontinued if serum ferritin increased above $800 \mathrm{ng} / \mathrm{mL}$ or $T_{\text {SAT }}$ increased above $50 \%$.

Study design

This was a single-arm, open-label, phase 3 study conducted at 27 centers in Latin America with the objective to investigate the efficacy, safety, and tolerability of once-monthly administration of C.E.R.A. in dialysis patients with chronic renal anemia. Participating study centers were located in Argentina, Brazil, Chile, Colombia, Ecuador, Mexico, Peru, Uruguay, and Venezuela.

The study was divided into 4 periods (Fig. 1): a stability verification period (SVP), a dose titration period (DTP), an efficacy evaluation period (EEP), and a safety follow-up period (FU).

Following receipt of written consent, patients were screened for eligibility over a 4-week period (SVP) during which $\mathrm{Hb}$ was assessed weekly and patients continued to receive epoetin alfa at the same weekly dose as prior to screening. Baseline $\mathrm{Hb}$ was defined as the mean of all $\mathrm{Hb}$ values measured during the SVP and was assessed under conditions of stable epoetin

Fig. 1 Study design

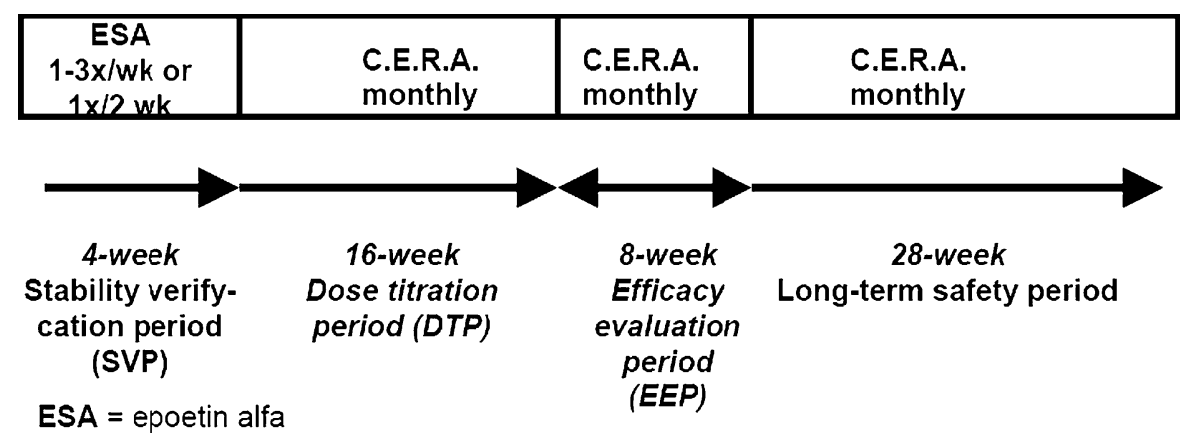


alfa dosage. Patients with a stable $\mathrm{Hb}$ concentration between 10.5 and $12.5 \mathrm{~g} / \mathrm{dL}$ were eligible to enter the DTP. Eligible patients provided a medical history including the etiology of CKD, concomitant diseases, concomitant medications, and previous treatments for anemia.

Eligible patients received a starting dose of C.E.R.A. that was based on the epoetin alfa dose administered during the week preceding the switch to the study drug. The DTP lasted 16 weeks (weeks 1-16), during which C.E.R.A. was administered every 4 weeks (i.e., weeks $4,8,12$, and 16). Dose adjustments were made if a patient presented with $\mathrm{a} \mathrm{Hb}$ concentration that was $>14$ or $<9 \mathrm{~g} / \mathrm{dL}$, or if the difference between two consecutive $\mathrm{Hb}$ measurements was $>2 \mathrm{~g} / \mathrm{dL}$. Dose adjustments for safety reasons were permitted at any time point during the study. An 8-week EEP (weeks 17-24) followed the DTP to assess $\mathrm{Hb}$ stability. A 28-week follow-up to monitor long-term patient safety followed the EEP.

\section{Study parameters}

The primary end point was the proportion of patients maintaining a mean $\mathrm{Hb}$ concentration $(\mathrm{g} / \mathrm{dL})$ within $\pm 1 \mathrm{~g} / \mathrm{dL}$ of their reference $\mathrm{Hb}$ and between 10.5 and $12.5 \mathrm{~g} / \mathrm{dL}$ during the EEP. Secondary efficacy variables included: (1) the change in mean $\mathrm{Hb}$ concentration between baseline and the EEP, (2) the proportion of patients maintaining an average $\mathrm{Hb}$ concentration within the range of $10.5-12.5 \mathrm{~g} / \mathrm{dL}$ throughout the $\mathrm{EEP}$, (3) the mean time spent in the $\mathrm{Hb}$ range of $10.5-12.5 \mathrm{~g} / \mathrm{dL}$ during the EEP, and (4) the proportion of patients requiring any dose adjustment during the dose titration and evaluation periods. In addition, the overall incidence of adverse events was included in a safety evaluation.

Parameters assessed at every visit included $\mathrm{Hb}$ concentration, hematocrit, and vital signs. Additional assessments performed at week 4 and at the final visit (or premature withdrawal) included an electrocardiogram (ECG) and a test for anti-erythropoietin antibodies. At study weeks 8, 16, 24, 32, 40, and 48, additional laboratory, and iron parameters were assessed, including white blood cell and platelet count and the concentrations of serum creatinine, albumin, C-reactive protein (CRP), potassium phosphate, serum iron, ferritin and transferrin or total iron-binding capacity (TIBC). At week 16, patients underwent an additional physical examination and dialysis adequacy was re-assessed. For DP patients, the dialysis adequacy was evaluated weekly. Adverse events, concomitant medications, and treatments were recorded throughout the study.

Statistical analyses

Analysis of the primary objective was performed on the per protocol (PP) population. Patients were excluded from the PP population if they had fewer than three recorded hemoglobin values during the EEP, missed an administration of C.E.R.A. in weeks 16-24, withdrew before the end of the EEP, or had inadequate iron status during the EEP, defined as a mean serum ferritin $\leq 100 \mathrm{ng} / \mathrm{mL}$ or a mean $T_{\text {SAT }}$ $\leq 20 \%$ or mean hypochromic RBCs $\geq 10 \%$. An additional analysis was performed using the data from the intent-to-treat (ITT) population to test the robustness of the results. The ITT population was comprised of patients who received at least one dose of C.E.R.A. and for whom data for at least one follow-up variable was available. Data missing at the end of the EEP was handled using the last value carried forward method (LOCF). The $95 \%$ exact confidence interval used for the response rate was calculated using the KlopperPearson method. Analyses of secondary efficacy variables were performed using data from the ITT population and were only descriptive.

Statistical power estimates were based on an initial estimate of approximately $70 \%$ from a previous study [14] and a two-sided $95 \%$ confidence interval. In order to estimate the true percentage of patients maintaining their average $\mathrm{Hb}$ concentration within $\pm 1 \mathrm{~g} / \mathrm{dL}$ of their reference $\mathrm{Hb}$, a sample size of 200 patients would be necessary. This would enable adverse events with a true incidence of $\geq 0.8 \%$ to be detected with a power of at least $80 \%$.

\section{Results}

Study population

A total of 261 patients with CKD from 27 centers in Argentina, Brazil, Chile, Colombia, Ecuador, Mexico, Peru, Uruguay, and Venezuela were screened between October 2007 and March 2009. Of these, 163 patients entered the treatment period and 102 completed the prescribed course of C.E.R.A. medication, while 61 
Fig. 2 Study flow diagram and patient disposition

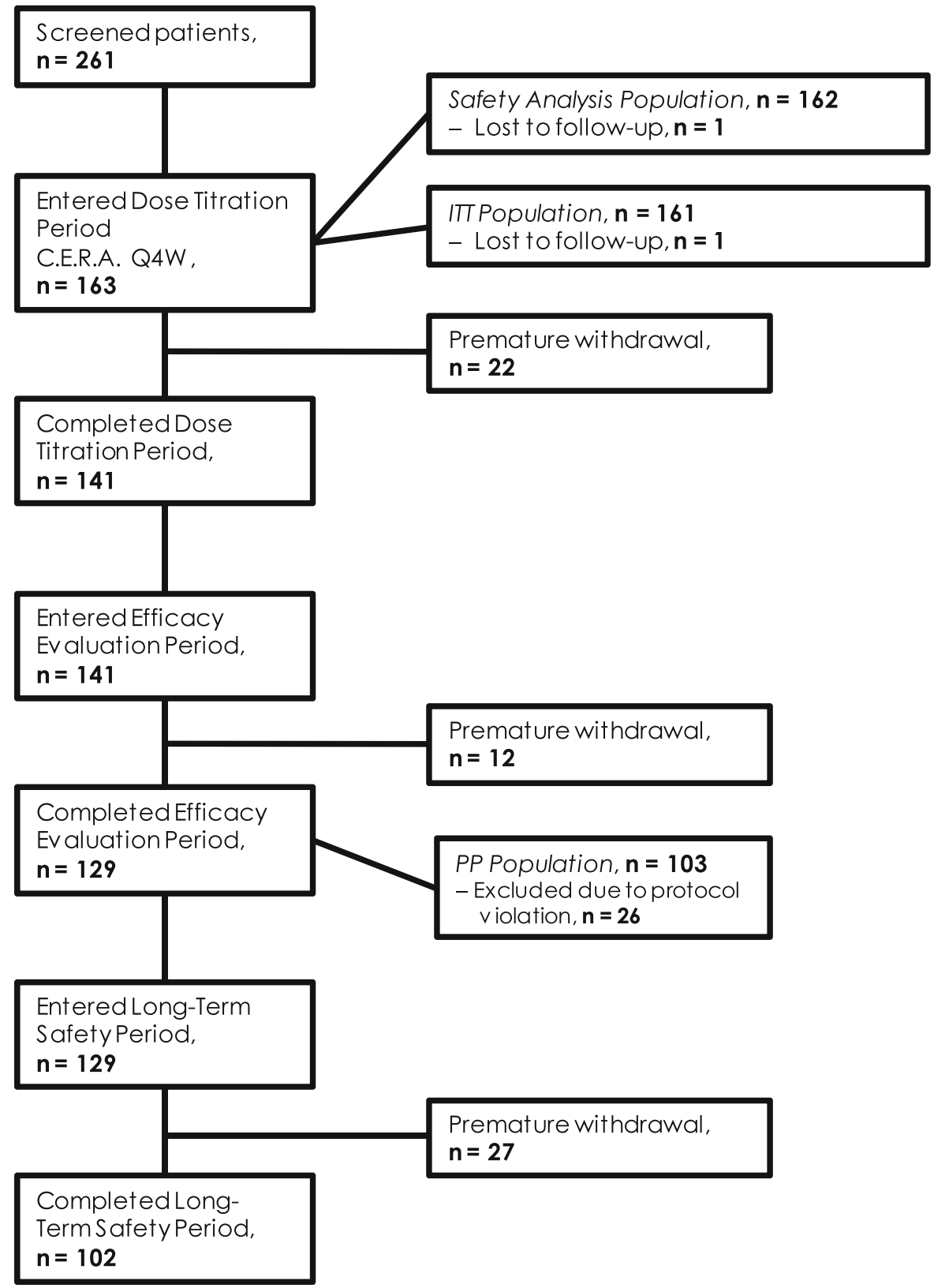

patients prematurely withdrew from the study (Fig. 2). The most common reasons for early withdrawal were safety-related reasons (20 patients) and protocol violations (15 patients).

The PP population comprised 103 patients and the ITT and safety populations consisted of 161 and 162 patients, respectively. The main reasons for exclusion from the PP population were having missed an administration of the study drug $(n=56)$, having fewer than $3 \mathrm{Hb}$ values during the $\operatorname{EEP}(n=27)$, requiring a blood transfusion during the DTP or EEP $(n=7)$, having a baseline $\mathrm{Hb}$ value not between 10.5 and $12.5 \mathrm{~g} / \mathrm{dL}(n=6)$, and deviation from a planned administration date by more than 10 days $(n=6)$.

The ITT population comprised 67 female $(42 \%)$ and $94(58 \%)$ male patients. The median age at the time of receipt of informed consent was 54 years. The most common causes of CKD in the safety population were hypertension/large vessel disease (41\%) 
Table 1 Baseline characteristics of safety population $(n=162)$

\begin{tabular}{lc}
\hline Male, $n(\%)$ & $94(58)$ \\
Median age, years (range) & $55(20-92)$ \\
Median weight, kg (range) & $67(42-104)$ \\
Mean Hb, g/dL (SD) & $11.4( \pm 0.6)$ \\
Mean serum ferritin, $\mu \mathrm{g} / \mathrm{L}(\mathrm{SD}), n=157$ & $592( \pm 421)$ \\
Mean iron, $\mu \mathrm{mol} / \mathrm{L}(\mathrm{SD}), n=159$ & $13.9( \pm 6.3)$ \\
Mean TIBC, $\mu \mathrm{mol} / \mathrm{L}(\mathrm{SD}), n=97$ & $38.5( \pm 10.4)$ \\
Mean transferrin, g/L(SD), $n=75$ & $1.8( \pm 0.5)$ \\
Mean $T_{\mathrm{SAT}}, \%(\mathrm{SD}), n=135$ & $35( \pm 19)$ \\
Median CRP, mg/L (min and max), $n=113$ & $8.3(0.0 ; 816)$ \\
Median Kt/V (interquartile range), $n=134$ & $1.5(1.3-1.8)$ \\
Primary causes of CKD, $n(\%)$ & \\
Hypertension/large vessel disease & $67(41)$ \\
Diabetes & $49(30)$ \\
Undefined etiology & $26(16)$ \\
Glomerulonephritis & $22(14)$ \\
Other & $17(11)$ \\
Interstitial nephritis/pyelonephritis & $6(4)$ \\
Polycystic kidney disease & $6(4)$ \\
Other hereditary/congenital diseases & $5(3)$ \\
Neoplasms/tumors & $3(2)$ \\
Secondary glomerulonephritis/vasculitis & $2(1)$ \\
\hline
\end{tabular}

Unless otherwise indicated; $H b$ hemoglobin, $T I B C$ total ironbinding capacity, $T_{S A T}$ transferrin saturation, $C R P$ C-reactive protein, $C K D$ chronic kidney disease

followed by diabetic nephropathy (30\%). The mean baseline $\mathrm{Hb}$ concentration among patients in the safety population was $11.4 \mathrm{~g} / \mathrm{dL}$. A summary of the safety population patient characteristics at baseline, including laboratory values and iron status, is provided in Table 1.

All patients were undergoing dialysis at the time of study entry; $88 \%$ were receiving hemodialysis and $12 \%$ were receiving peritoneal dialysis.

Prior to the start of the DTP, all patients were receiving treatment with epoetin alfa. The median dose of epoetin alfa during the SVP was 6,000 IU per week. One hundred and eighteen patients (73\%) received iron supplements prior to study entry.

Study treatment

The mean cumulative total dose of C.E.R.A. up to week 20 was $807 \mu \mathrm{g}( \pm 291)$ and the median was $720 \mu \mathrm{g}$. The mean monthly dose of C.E.R.A. was

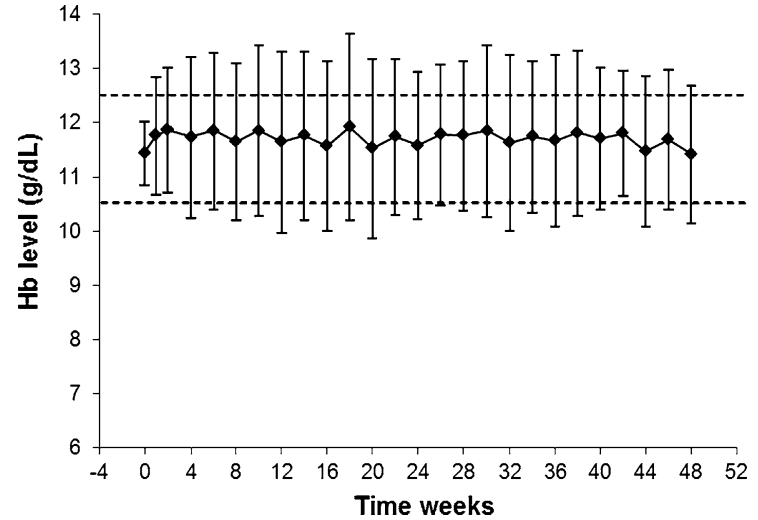

Fig. 3 Mean $\mathrm{Hb}$ values (safety population)

$135.5 \mu \mathrm{g}( \pm 40.2)$ during the DTP and $132.7 \mu \mathrm{g}$ $( \pm 77.2)$ during the EEP. The median monthly dose remained constant at $120 \mu \mathrm{g}$ during the titration period and during the EEP.

Primary efficacy evaluation

Evaluation of the primary objective was performed on the PP population $(n=103)$. The mean Hb concentration at baseline was $11.5 \mathrm{~g} / \mathrm{dL}( \pm 0.57)$. During the EEP, the mean $\mathrm{Hb}$ concentration was $11.7 \mathrm{~g} / \mathrm{dL}$ ( \pm 1.19$)$ (Fig. 3). Forty-five patients $(43.7 \%)$ maintained a mean $\mathrm{Hb}$ concentration within $\pm 1 \mathrm{~g} / \mathrm{dL}$ of their reference $\mathrm{Hb}$ value and between 10.5 and $12.5 \mathrm{~g} / \mathrm{dL}$ during the EEP.

Secondary efficacy evaluations

Patient $\mathrm{Hb}$ concentrations in the ITT population ( $n=161)$ also stayed close to baseline levels but showed slight fluctuations. The proportion of patients maintaining a mean $\mathrm{Hb}$ concentration within $\pm 1 \mathrm{~g} / \mathrm{dL}$ of their reference $\mathrm{Hb}$ value and between 10.5 and $12.5 \mathrm{~g} / \mathrm{dL}$ during the EEP was $36 \%$. The proportion of patients who only maintained a mean $\mathrm{Hb}$ level within $\pm 1 \mathrm{~g} / \mathrm{dL}$ of their reference $\mathrm{Hb}$ value was $51 \%$. The mean change in the time-adjusted average of $\mathrm{Hb}$ concentration between baseline (SVP) and the EEP was $0.08 \mathrm{~g} / \mathrm{dL}$ $( \pm 1.48)$. The median time spent in the $\mathrm{Hb}$ target range of $10.5-12.5 \mathrm{~g} / \mathrm{dL}$ during the EEP was 30 days.

On the average, there were 2.3 dose changes per patient in 28 weeks of treatment, covering 7 C.E.R.A. scheduled administrations. The dose of C.E.R.A. needed to be adjusted in 106 patients $(66 \%)$ during the DTP. The dose was decreased in 39 patients, 
increased in 35 patients, and increased and decreased in 32 patients. Of the one hundred and forty-one patients who entered the EEP, the dose of C.E.R.A. needed to be adjusted in 72 patients (51\%), was increased in 34 patients $(24 \%)$ and decreased in 27 patients $(19 \%)$. The dose needed to be increased and decreased in 11 patients $(8 \%)$.

Iron status

Iron supplementation was given to 58 patients (36\%) during the study. Iron supplements were primarily given in the form of saccharated iron oxide (82\% of supplemented patients), but also as iron dextran $(13 \%)$, oral iron $(4 \%)$, or ferric sodium gluconate complex (1\%). Throughout the study, the iron levels in the patients, as reflected by the mean serum ferritin concentration and the mean transferrin saturation, were maintained at a constant high level within the predetermined ranges of serum ferritin $>100$ and $<800 \mathrm{ng} / \mathrm{mL}$ and $T_{\mathrm{SAT}}>20$ and $<50 \%$. High standard deviations were present, however, at all time points (Figs. 4, 5).

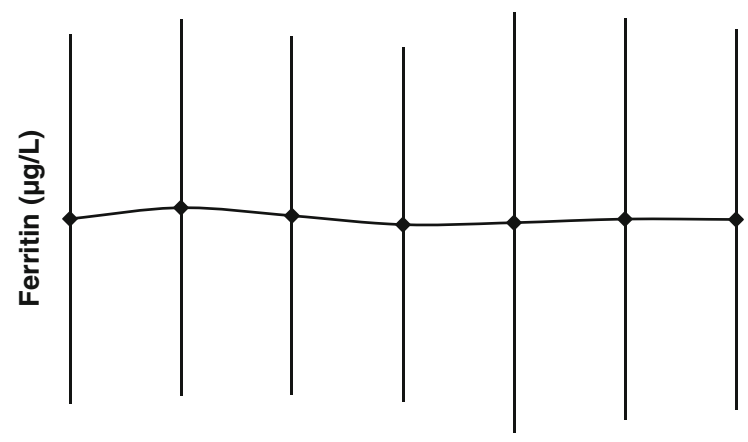

Time weeks

Fig. 4 Mean serum ferritin levels (safety population)

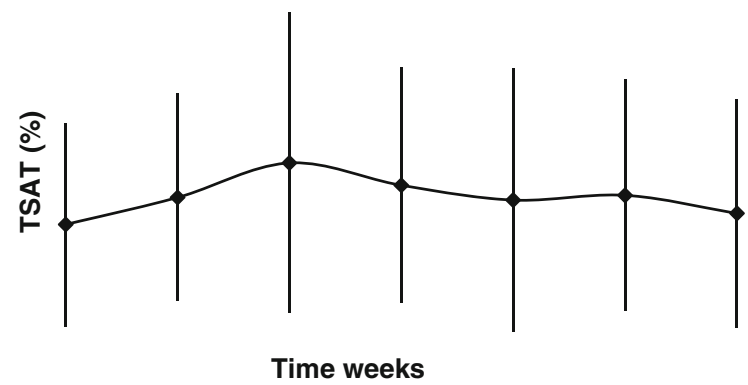

Fig. 5 Mean transferrin saturation $\left(T_{\mathrm{SAT}}\right)$ levels (safety population)
During the study, median CRP levels varied between 6.3 and $10.1 \mathrm{mg} / \mathrm{L}$.

Safety and tolerability

One hundred and twenty patients (74\%) reported 416 adverse events (AEs) that occurred during treatment with C.E.R.A. The most commonly reported AEs were hypertension (13\%), diarrhea (7\%), and hypotension (6\%). The body system classes most affected were infections and infestations (33\% of all patients); vascular disorders $(25 \%)$; gastrointestinal disorders (24\%); and injury, poisoning, and procedural complications $(17 \%)$. Nine patients experienced a total of 10 AEs that were reported by the investigators as related to the study treatment. These included one case each of anemia, constipation, diarrhea, arteriovenous fistula thrombosis, wound secretion, hemoglobin decreased, alopecia, hyperhidrosis, hypertension, and thrombosis. However, some of these may not be actually related to the study drug itself.

Seventy-eight serious AEs (SAEs) were reported in 53 patients $(33 \%)$ during the C.E.R.A. treatment period. Four SAEs were considered to be drug-related. Twenty-seven SAEs began during the titration period, 16 occurred during the EEP. Fourteen patients died after the start of C.E.R.A. treatment. All deaths were unrelated to the study drug.

Anti-erythropoietin antibodies were not detected in any patients during the study.

\section{Discussion}

The results of this study demonstrate that stable $\mathrm{Hb}$ concentrations can be maintained in CKD patients on dialysis after switching to once-monthly C.E.R.A., irrespective of previous ESA treatment. In summary, 45 patients $(43.7 \%)$ maintained their mean $\mathrm{Hb}$ concentration within $\pm 1 \mathrm{~g} / \mathrm{dL}$ of their reference $\mathrm{Hb}$ value and between 10.5 and $12.5 \mathrm{~g} / \mathrm{dL}$ during the EEP. In the ITT population, the proportion of patients maintaining their mean $\mathrm{Hb}$ concentration within \pm 1 $\mathrm{g} / \mathrm{dL}$ of their reference $\mathrm{Hb}$ value and between 10.5 and $12.5 \mathrm{~g} / \mathrm{dL}$ during the EEP was lower (36 \%). The 2007 KDOQI anemia guidelines as well as the 2009 SLANH anemia guidelines state that the upper $\mathrm{Hb}$ limit during treatment should be $12 \mathrm{~g} / \mathrm{dL}$. The present protocol established $12.5 \mathrm{~g} / \mathrm{dL}$ for $\mathrm{Hb}$ upper target, 
which indeed is $0.5 \mathrm{~g} / \mathrm{dL}$ higher than the nowadays recommended upper limit.

The lower result for the ITT population may be attributed to the fact that more patients in the ITT population missed study drug administrations compared to the PP population.

One limitation of the study was that the route for the administration of iron supplementation was left to the discretion of the individual study centers. CKD patients on dialysis often present with high levels of inflammation and oxidative stress [17]. Consequently, the absorption of oral iron in the intestine is limited or prevented [18]. Thus, the route for the administration of iron can have a significant effect on its utilization.

The results of this study show similarities with those of other studies demonstrating that oncemonthly C.E.R.A. provides stable maintenance of $\mathrm{Hb}$ concentrations in patients with chronic renal anemia [18-20]. Carrera et al. reported that $64.1 \%$ of renal anemia patients undergoing hemodialysis maintained a $\mathrm{Hb}$ concentration $\geq 10.5 \mathrm{~g} / \mathrm{dL}$ and within $1 \mathrm{~g} / \mathrm{dL}$ of baseline values while receiving maintenance therapy with C.E.R.A [20]. This compared with only $40.1 \%$ of patients who received darbepoetin alfa every two weeks [18]. Similarly, in a study of patients with CKD on dialysis, Sulowitz et al. found that $66.1 \%$ of patients treated with once-monthly C.E.R.A. maintained a $\mathrm{Hb}$ concentration within $1 \mathrm{~g} / \mathrm{dL}$ of their baseline value [21]. Levin et al. [19] found that $67 \%$ of CKD patients on dialysis treated with epoetin maintained a $\mathrm{Hb}$ concentration within $1 \mathrm{~g} / \mathrm{dL}$ of their baseline value over an 8 -week evaluation period. In another study of CKD patients on dialysis, Spinowitz et al. [22] compared twice-monthly C.E.R.A. with 1-3 times per week epoetin alfa and found that the proportion of patients maintaining a mean $\mathrm{Hb}$ concentration within $1 \mathrm{~g} / \mathrm{dL}$ of the baseline value was $68.5 \%$ for C.E.R.A.-treated and $67.7 \%$ for epoetin alfa-treated patients. Although these studies were performed in comparable patient populations, the percentage of patients who remained within $1 \mathrm{~g} / \mathrm{dL}$ of their baseline value was slightly higher than in the present study (i.e., $51 \%$ of patients).

Variability in $\mathrm{Hb}$ values over time is a common phenomenon in patients on dialysis and has been shown to be associated with increased mortality. Two recent studies of patients undergoing hemodialysis and stable ESA therapy in the United Kingdom and Australia found that all patients experienced at least
1 fluctuation outside target $\mathrm{Hb}$ levels $(11-12 \mathrm{~g} / \mathrm{dL}$ in Australian study and 11-12.5 g/dL in the U.K. study) and $68-73 \%$ had at least 3 fluctuations over a 12-month period [23]. The risk associated with this fluctuation was revealed in a retrospective analysis of 35,000 hemodialysis patients: each $1 \mathrm{~g} / \mathrm{dL}$ increase in $\mathrm{Hb}$ variability corresponded to a $33 \%$ increase in mortality risk [13]. During the EEP of the present study, the mean fluctuation of $\mathrm{Hb}$ values was $0.62 \mathrm{~g} / \mathrm{dL}$. The only other study of C.E.R.A. that reported $\mathrm{Hb}$ fluctuation (other than an assessment of the proportion of patients whose $\mathrm{Hb}$ levels remained within set limits) was that of Canaud et al. They assessed $\mathrm{Hb}$ fluctuation by evaluating within-patient standard deviations for $\mathrm{Hb}$ concentration and arrived at similar results for patients treated with twice-monthly C.E.R.A. and those treated once-weekly or once every two weeks with darbepoetin alfa: 0.86 versus $0.76 \mathrm{~g} / \mathrm{dL}$ during titration and 0.63 versus $0.53 \mathrm{~g} / \mathrm{dL}$ during evaluation, respectively [24]. However, in the present study, fluctuation was calculated by assessing the differences between successive hemoglobin levels, and therefore, the results of the two studies cannot be directly compared.

The fact that $\mathrm{Hb}$ concentrations could be maintained in the desired range (in $44 \%$ of patients) without increasing the dose of C.E.R.A. suggests that patients had adequate iron available for hematopoiesis. This is likely the result of monitoring patient iron levels and provision of iron supplements when necessary. Indeed, throughout the study, the serum ferritin and $T_{\mathrm{SAT}}$ values were adequate, however, with ample variations. A contributing factor for this variation could be the intravenously administered iron supplementation. Furthermore, one must consider that ferritin levels are influenced by inflammatory processes. Elevated CRP levels in the current study population are indicative of such inflammatory processes, which is known to affect the ferritin levels. The percentage of patients who received iron supplementation during the study was $36 \%$. This is substantially lower compared with reports from other studies of C.E.R.A. in CKD patients, which reported values of 92 [24], 85 [18], 82.4 [25], 77 [19], and $86 \%$ [22]. It is also lower compared with the number of patients treated with conventional ESAs who received iron supplementation in those studies: $85 \%$ of darbepoetin alfa-treated patients in the Carrera et al. [18] study and $93 \%$ of darbepoetin alfa-treated patients in the Canaud et al. 
[24] study. The reasons for the low percentage of patients receiving iron treatment in our study compared to the other studies are not readily identifiable.

The percentage of patients who experienced at least one AE in this study (74 \%) is somewhat lower than the reports (88-95\%) from other studies [18, 19, 21, 22, 24] of C.E.R.A. in similar patient populations. On the other hand, the percentage of patients experiencing SAEs was considerably lower. Seventy-eight SAEs were reported by $18 \%$ of patients during treatment with C.E.R.A. This compares with rates ranging from 31 to $46 \%$ reported in other studies [18, 19, 21, 22, 24]. The discrepancy is probably a consequence of the differences in study duration, patient population/ severity of disease, and/or in clinic practices.

The results of this study confirm that once-monthly C.E.R.A. treatment effectively maintains stable $\mathrm{Hb}$ concentrations in patients with chronic renal anemia undergoing dialysis with a good safety and tolerability profile.

LATINO Trial Investigators: Argentina: Luis Gaite, Daniel Di Tullio, Pablo A. Novoa, Osvaldo Hermida, Liliana Andrade. Chile: Aquiles Jara, Juan Carlos Flores. Ecuador: Rómulo Campaña. Mexico: Tommaso Bochicchio, Francisco Ruiz, Alejandro Valdes. Peru: Edmundo Alva, Benjamín Herrada, Alberto Koga. Venezuela: Ana Ma Sananez. Uruguay: Liliana Chifflet.

Acknowledgments All authors read and approved the final version of the report. This trial was sponsored by F. Hoffman-La Roche Ltd., Basel, Switzerland. Editorial support was provided by Archimed Medical Communication AG, Zofingen, Switzerland, supported by F. Hoffman-La Roche.

Conflict of interest Ricardo Correa-Rotter, who is the corresponding author, has received honoraria from and has given lectures as invited speaker for Roche, Amgen, Abbott, Genzyme, Novartis, and Fresenius Medical care. He has also acted as member or the Executive Committee of the study Evolve, sponsored by Amgen. De declares no conflict of interest for the present manuscript. No financial conflict of interest exists for the other authors.

Open Access This article is distributed under the terms of the Creative Commons Attribution License which permits any use, distribution, and reproduction in any medium, provided the original author(s) and the source are credited.

\section{References}

1. Leaf DE, Goldfarb DS (2009) Interpretation and review of health-related quality of life data in CKD patients receiving treatment for anemia. Kidney Int 75:15-24
2. Thorp ML, Johnson ES, Yang X, Petrik AF, Platt R, Smith DH (2009) Effect of anaemia on mortality, cardiovascular hospitalizations and end-stage renal disease among patients with chronic kidney disease. Nephrology (Carlton.) 14:240 246

3. Cueto-Manzano AM (2003) Peritoneal dialysis in Mexico. Kidney Int Suppl 63(Suppl 83):S90-S92

4. Cueto-Manzano AM, Rojas-Campos E (2007) Status of renal replacement therapy and peritoneal dialysis in Mexico. Perit Dial Int 27:142-148

5. Garcia-Garcia G, Briseno-Renteria G, Luquin-Arellan VH, Gao Z, Gill J, Tonelli M (2007) Survival among patients with kidney failure in Jalisco, Mexico. J Am Soc Nephrol 18:1922-1927

6. Paniagua R, Ramos A, Fabian R, Lagunas J, Amato D (2007) Chronic kidney disease and dialysis in Mexico. Perit Dial Int 27:405-409

7. Pecoits-Filho R, Abensur H, Cueto-Manzano AM, Dominguez J, vino Filho JC, Fernandez-Cean J et al (2007) Overview of peritoneal dialysis in Latin America. Perit Dial Int 27:316-321

8. Locatelli F, Aljama P, Barany P, Canaud B, Carrera F, Eckardt KU et al (2004) Revised European best practice guidelines for the management of anaemia in patients with chronic renal failure. Nephrol Dial Transplant 19(Suppl 2):ii1-ii47

9. Halstenson CE, Macres M, Katz SA, Schnieders JR, Watanabe M, Sobota JT et al (1991) Comparative pharmacokinetics and pharmacodynamics of epoetin alfa and epoetin beta. Clin Pharmacol Ther 50:702-712

10. Macdougall IC, Robson R, Opatrna S, Liogier X, Pannier A, Jordan P et al (2006) Pharmacokinetics and pharmacodynamics of intravenous and subcutaneous continuous erythropoietin receptor activator (C.E.R.A.) in patients with chronic kidney disease. Clin J Am Soc Nephrol 1:12111215

11. Ebben JP, Gilbertson DT, Foley RN, Collins AJ (2006) Hemoglobin level variability: associations with comorbidity, intercurrent events, and hospitalizations. Clin J Am Soc Nephrol 1:1205-1210

12. Roche (2006) RO0503821 (Methoxy polyethylene glycolepoetin beta) investigator's brochure

13. Yang W, Israni RK, Brunelli SM, Joffe MM, Fishbane S, Feldman HI (2007) Hemoglobin variability and mortality in ESRD. J Am Soc Nephrol 18:3164-3170

14. Fishbane S, Berns JS (2005) Hemoglobin cycling in hemodialysis patients treated with recombinant human erythropoietin. Kidney Int 68:1337-1343

15. Vaziri ND, Zhou XJ (2009) Potential mechanisms of adverse outcomes in trials of anemia correction with erythropoietin in chronic kidney disease. Nephrol Dial Transplant 24:1082-1088

16. KDOQI (2007) KDOQI clinical practice guideline and clinical practice recommendations for anemia in chronic kidney disease: 2007 update of hemoglobin target. Am J Kidney Dis 50:471-530

17. Munoz M, Villar I, Garcia-Erce JA (2009) An update on iron physiology. World J Gastroenterol 15:4617-4626

18. Carrera F, Lok CE, de Francisco A, Locatelli F, Mann JF, Canaud B et al (2010) Maintenance treatment of renal anaemia in haemodialysis patients with methoxy 
polyethylene glycol-epoetin beta versus darbepoetin alfa administered monthly: a randomized comparative trial. Nephrol Dial Transplant 25:4009-4017

19. Levin NW, Fishbane S, Canedo FV, Zeig S, Nassar GM, Moran JE et al (2007) Intravenous methoxy polyethylene glycol-epoetin beta for haemoglobin control in patients with chronic kidney disease who are on dialysis: a randomised non-inferiority trial (MAXIMA). Lancet 370:1415-1421

20. Locatelli F, Villa G, de Francisco AL, Albertazzi A, Adrogue HJ, Dougherty FC et al (2007) Effect of a continuous erythropoietin receptor activator (C.E.R.A.) on stable haemoglobin in patients with CKD on dialysis: once monthly administration. Curr Med Res Opin 23:969-979

21. Sulowicz W, Locatelli F, Ryckelynck JP, Balla J, Csiky B, Harris K et al (2007) Once-monthly subcutaneous C.E.R.A. maintains stable hemoglobin control in patients with chronic kidney disease on dialysis and converted directly from epoetin one to three times weekly. Clin J Am Soc Nephrol 2:637-646
22. Spinowitz B, Coyne DW, Lok CE, Fraticelli M, Azer M, Dalal S et al (2008) C.E.R.A. maintains stable control of hemoglobin in patients with chronic kidney disease on dialysis when administered once every two weeks. Am J Nephrol 28:280-289

23. Roche A, Macdougall IC, Walker RG (2009) Haemoglobin fluctuations in patients on haemodialysis treated with ESAs: clinical observations from two centres. Curr Med Res Opin 25:2971-2976

24. Canaud B, Mingardi G, Braun J, Aljama P, Kerr PG, Locatelli $\mathrm{F}$ et al (2008) Intravenous C.E.R.A. maintains stable haemoglobin levels in patients on dialysis previously treated with darbepoetin alfa: results from STRIATA, a randomized phase III study. Nephrol Dial Transplant 23:3654-3661

25. Fliser D, Kleophas W, Dellanna F, Winkler RE, Backs W, Kraatz U et al (2010) Evaluation of maintenance of stable haemoglobin levels in haemodialysis patients converting from epoetin or darbepoetin to monthly intravenous C.E.R.A.: the MIRACEL study. Curr Med Res Opin 26:1083-1089 